\title{
Investigation of alkaline hydrogen peroxide pretreatment and Tween 80 to enhance enzymatic hydrolysis of sugarcane bagasse
}

Hongdan Zhang ${ }^{1,2^{*}} \mathbb{0}$, Shihang Huang ${ }^{1}$, Weiqi Wei ${ }^{3}$, Jiajie Zhang ${ }^{1}$ and Jun Xie ${ }^{1}$

\begin{abstract}
Background: Due to the intact structure of lignocellulosic biomass, pretreatment was a prerequisite to improve the enzymatic hydrolysis by disrupting the recalcitrant lignocellulose and increasing the accessibility of cellulose to enzyme. In this study, an alkaline hydrogen peroxide (AHP) pretreatment of sugarcane bagasse with various loadings of $\mathrm{H}_{2} \mathrm{O}_{2}(1.25-6.25 \mathrm{wt} \%)$ at temperatures of $60-160^{\circ} \mathrm{C}$ was proposed to degrade hemicellulose/lignin and improve the enzymatic digestibility.

Results: It was found that increasing $\mathrm{H}_{2} \mathrm{O}_{2}$ loadings during pretreatment lead to the enhancement of substrate digestibility, whereas the alkali (only $\mathrm{NaOH}$ )-pretreated solid generated higher glucose yield than that pretreated under AHP pretreatment with lower loading of $\mathrm{H}_{2} \mathrm{O}_{2}$. This enhancement of enzymatic digestibility was due to the degradation of hemicellulose and lignin. Furthermore, Tween 80 was added to promote enzymatic digestibility, however, the increased yields were different with various substrates and hydrolysis time. The highest glucose yield of $77.6 \%$ was obtained after pretreatment at $160{ }^{\circ} \mathrm{C}$ for 60 min with $6.25 \% \mathrm{H}_{2} \mathrm{O}_{2}$ and the addition of Tween 80 , representing $89.1 \%$ of glucose in pretreated substrate.

Conclusions: This study demonstrated that the AHP pretreatment could greatly enhance the enzymatic saccharification. The addition of Tween 80 played remarkable performances in promoting the glucose yield during enzymatic hydrolysis by stabilizing and protecting the enzyme activity. This study provided an economical feasible and gradual process for the generation of glucose, which will be subsequently converted to bioethanol and bio-chemicals.
\end{abstract}

Keywords: Sugarcane bagasse, Alkaline hydrogen peroxide pretreatment, Glucose, Tween 80

\section{Background}

Declining fossil fuels, higher demand for energy, and serious environmental problems had led to attempts to identify sustainable fuels derived from lignocellulosic biomass. Sugarcane bagasse is the fibrous material obtained after juice extraction from sugarcane [1]. Generally, they were discarded away, or fed into mill boiler, which were not favorable for the sustainable development of resource and environment [2]. The abundant

\footnotetext{
*Correspondence: hdzhang@scau.edu.cn

${ }^{1}$ College of Forestry and Landscape Architecture, Key Laboratory

of Energy Plants Resource and Utilization, Ministry of Agriculture, South China Agricultural University, Guangzhou 510642, People's Republic

of China

Full list of author information is available at the end of the article
}

carbohydrates (such as cellulose and hemicellulose) and lignin in sugarcane bagasse are promising sources for the production of value-added chemicals and fuels by biorefinery processes. However, the rigid and intact structure of lignocellulosic biomass made it difficult to break down to hexose and subsequently ferment to bio-based fuels and chemicals. Consequently, several steps including pretreatment were proposed to enhance the enzymatic digestibility by breaking the structure down and improving the accessibility of enzyme to cellulose [3, 4].

Recently, various pretreatments using dilute acid/alkali, liquid hot water, ethanol, and ionic liquids had been proposed [5]. Numerous research have concentrated in alkaline pretreatment due to the lower work temperature and pressure, less corrosion, simpler reactors, the reuse 
of residual alkali, minimal formation of inhibitors, and preserving carbohydrates considerably [6, 7]. Alkali pretreatments could enhance the enzymatic digestibility by swelling fibers, breaking ester bonds of lignin-carbohydrate complexes, solubilizing lignin molecules, increasing the surface area, and providing more cellulose for the accessibility of enzyme. Among the alkali pretreatments reported so far, AHP pretreatment was appealing to the effective degradation of lignin from lignocellulosic biomass because $\mathrm{H}_{2} \mathrm{O}_{2}$ could degrade to oxygen and water without any residues left in the process [8]. Li et al. [6] investigated the plant cell wall recalcitrance features of diverse bioenergy feedstocks during AHP pretreatment with 12.5-50 wt $\% \mathrm{H}_{2} \mathrm{O}_{2}$, suggesting that major alterations in structure, compositional organization, and enzymatic hydrolysis in goldenrod and corn stover rather than in hybrid poplar. The ultrasonic-assisted alkali peroxide pretreatment of Jerusalem artichoke stem released $79.4 \%$ of hextose and showed a highest total sugar concentration of $10.4 \mathrm{~g} / \mathrm{L}$, which were 2.4 and 2.6 times higher than that obtained from the control, respectively. This enhancement was ascribed to the distinctive extraction of pectin polymers and lignin, accompanying with great alterations of cellulose degree polymerization (DP) and crystalline index (CrI) [9].

To achieve high cellulose digestibility, AHP pretreatment were carried out with relatively high reaction temperatures, large amount of chemicals, or sequential two-stage pretreatments. It was reported that AHP treatment of Douglas fir at $180{ }^{\circ} \mathrm{C}$ for $30 \mathrm{~min}$ with $10 \mathrm{wt} \%$ loading of $\mathrm{H}_{2} \mathrm{O}_{2}$ generated cellulose-to-glucose yield of $95 \%$ [10]. The alkaline peroxide delignification of corn stover were conducted at $50{ }^{\circ} \mathrm{C}$ for $3 \mathrm{~h}$ over the range of 3-50 wt $\% \mathrm{H}_{2} \mathrm{O}_{2}$, when the $\mathrm{H}_{2} \mathrm{O}_{2}$ loading reached $25 \mathrm{wt} \%$, about $90 \%$ of glucose and $80 \%$ of xylose were liberated after a digestion period of $120 \mathrm{~h}$ [11]. Yuan et al. [12] investigated the bamboo pretreatment with $\mathrm{NaOH}$ preextraction $(8 \mathrm{wt} \%)$ at $100{ }^{\circ} \mathrm{C}$ for $3 \mathrm{~h}$ followed by AHP with $4 \mathrm{wt} \% \mathrm{H}_{2} \mathrm{O}_{2}$ at $75{ }^{\circ} \mathrm{C}$ for $3 \mathrm{~h}$, suggesting that the pretreated substrate recovered $87 \%$ of the inherent sugars in native bamboo with enzyme loading of $9 \mathrm{FPU} / \mathrm{g}$ cellulose. Though visible strides had been made in evaluating the influence of AHP pretreatment on the deconstruction and enzymatic digestibility of lignocellulosic biomass, a comprehensive picture of AHP pretreatment under large-scale temperatures with different dosage of $\mathrm{H}_{2} \mathrm{O}_{2}$, and the comparison with only $\mathrm{NaOH}$ pretreatment on the enzymatic hydrolysis and how they affected the cellulose accessibility was still unclear.

It is generally recognized that the addition of additives such as non-ionic surfactants, polymers and non-catalytic proteins could enhance the enzymatic hydrolysis, reduce the enzyme loading, or shorten the hydrolysis time [13-15]. Yan et al. [14] reported that by adding BSA to dilute acid pretreated poplar generated more than $90 \%$ glucose and 95\% xylose during enzymatic digestibility process. In our previous study, the addition of Tween 80, BSA, PEG 4000, sulfonated lignin, and organosolv lignin on enzymatic hydrolysis of pretreated substrates were compared, indicating that Tween 80 performed excellent increment in liberating glucose [13]. The boost to enzymatic digestibility by Tween 80 was due to its capacity in swelling fibers, increasing surface area, and improving the cellulase accessibility to cellulose [15].

Though the positive influence of Tween 80 on the enzymatic saccharification had been reported in previous research, the comparison saccharification of $\mathrm{NaOH}$ and AHP-pretreated substrates with the addition of Tween 80 under different temperatures were scarce. Thus, the objective of this study was to investigate the influence of AHP pretreatment under various conditions $\left(60-160{ }^{\circ} \mathrm{C}\right.$, $1-4 \mathrm{~h}, 0-6.25 \mathrm{wt} \% \mathrm{H}_{2} \mathrm{O}_{2}$ ) on the saccharification of pretreated substrates. Furthermore, the structural modifications were evaluated to determine their influence on saccharification using X-ray diffraction (XRD), scanning electron microscopy (SEM), fourier transform infrared spectroscopy (FT-IR), and thermogravimetric (TG) analysis. In addition, the effect of Tween 80 on the enzymatic saccharification of AHP and $\mathrm{NaOH}$-pretreated substrates were investigated to determine their mechanism.

\section{Results and discussion}

\section{Compositional analysis after pretreatment}

The composition of sugarcane bagasse pretreated using $\mathrm{NaOH}$ and AHP pretreatment with various temperatures and their influence on solid recovery, cellulose retention, and the degradation of hemicellulose/lignin were summarized in Table 1 . As shown, when the sugarcane bagasse was pretreated with only $3 \% \mathrm{NaOH}$ at $60{ }^{\circ} \mathrm{C}$ for $4 \mathrm{~h}$, the solid recovery was $90.4 \%$, the removal of xylan (25.5\%) and AIL (11.9\%) contributed to the solid loss, resulting in the reduced contents of xylan and AIL, and the increment of glucan content in pretreated substrate. Meanwhile, the glucan recovery reached $98.5 \%$. As the pretreatment temperature was elevated from 60 to $120{ }^{\circ} \mathrm{C}$, there was a small decline in solid recovery, and the removal of xylan increased gradually to $30.0 \%$. However, obvious changes in glucan recovery and delignification were not observed. When the pretreatment temperature was ascended to $160{ }^{\circ} \mathrm{C}$, the recoveries of solid and glucan were decreased gradually to $84.8 \%$ and $91.6 \%$, respectively. At the same time, the removal of xylan and AIL increased to $37.4 \%$ and $16.3 \%$. This phenomenon indicated that delignification was not sensitive to the temperature during $3 \% \mathrm{NaOH}$ pretreatment. 
Table 1 Chemical composition of sugarcane bagasse before and after pretreatment under different conditions

\begin{tabular}{|c|c|c|c|c|c|c|c|}
\hline \multirow[t]{2}{*}{ Pretreatment conditions } & \multirow[t]{2}{*}{ Solid recovery } & \multicolumn{2}{|c|}{ Glucan (\%) } & \multicolumn{2}{|c|}{ Xylan (\%) } & \multicolumn{2}{|l|}{ AIL (\%) } \\
\hline & & Content & Recovery & Content & Removal & Content & Removal \\
\hline Raw material & - & 41.2 & - & 20.2 & - & 22.0 & - \\
\hline $60^{\circ} \mathrm{C}+\mathrm{NaOH}$ & 90.4 & 44.9 & 98.5 & 16.6 & 25.5 & 21.4 & 11.9 \\
\hline $60^{\circ} \mathrm{C}+\mathrm{NaOH}+6.25 \% \mathrm{H}_{2} \mathrm{O}_{2}$ & 86.3 & 44.3 & 92.8 & 14.9 & 36.2 & 21.0 & 17.6 \\
\hline $120^{\circ} \mathrm{C}+\mathrm{NaOH}$ & 89.9 & 45.2 & 98.6 & 15.7 & 30.0 & 21.8 & 11.0 \\
\hline $120^{\circ} \mathrm{C}+\mathrm{NaOH}+6.25 \% \mathrm{H}_{2} \mathrm{O}_{2}$ & 76.5 & 48.6 & 90.3 & 13.6 & 48.7 & 21.3 & 26.0 \\
\hline $160^{\circ} \mathrm{C}+\mathrm{NaOH}$ & 84.8 & 44.7 & 91.6 & 14.9 & 37.4 & 21.7 & 16.3 \\
\hline $160^{\circ} \mathrm{C}+\mathrm{NaOH}+6.25 \% \mathrm{H}_{2} \mathrm{O}_{2}$ & 59.6 & 60.1 & 87.1 & 5.2 & 84.7 & 22.6 & 38.9 \\
\hline
\end{tabular}

When AHP pretreatment was conducted at $60{ }^{\circ} \mathrm{C}$ for $4 \mathrm{~h}$ with $3 \% \mathrm{NaOH}$ and $6.25 \% \mathrm{H}_{2} \mathrm{O}_{2}$, the solid recovery was $86.3 \%$, and the removal of xylan and AIL reached $36.2 \%$ and $17.6 \%$, which was higher than that pretreated with only $\mathrm{NaOH}$. This phenomenon was ascribed to the hydroxyl radicals produced from the decomposition of $\mathrm{H}_{2} \mathrm{O}_{2}$ at alkali condition which promoted the deconstruction of hemicellulose and lignin [16]. When the pretreatment temperature was elevated to $120{ }^{\circ} \mathrm{C}$, the solid recovery decreased to $76.5 \%$, ascribing to the widespread degradation of xylan (48.7\%) and AIL (26\%). However, $48.6 \%$ of glucan could be detected in pretreated substrate, indicating that $90 \%$ of glucan were retained after pretreatment. As the pretreatment temperature went on increasing to $160^{\circ} \mathrm{C}$, the solid recovery decreased sharply to $59.6 \%$ because of the large removal of xylan (84.7\%), suggesting that hemicellulose were effectively extracted during AHP pretreatment [17]. Though the glucan content in pretreated solid increased to $60.1 \%$, the recovery decreased to $87.1 \%$. Meanwhile, a decrease of AIL recovery was observed, which might be ascribed to the oxidation of phenolic and carbonyl structures in lignin by hydroxyl or superoxide anion radicals produced from the decomposition of $\mathrm{H}_{2} \mathrm{O}_{2}$ [18]. From these outcomes, it could know that the decomposition of hemicellulose and lignin was promoted with higher reaction temperature, especially in AHP pretreatment. The large degradation of hemicellulose/lignin resulted in the increment of surface area and pore volume, which allowed for the cellulase penetration and the enhancement of enzymatic saccharification $[17,19]$.

\section{Characterization of untreated and pretreated sugarcane bagasse}

$\mathrm{X}$-ray diffraction curves of untreated and pretreated substrates were used to calculate the crystallinity and cellulose crystallites size, and the results were depicted in Fig. 1. The CrI of native material was $40.4 \%$. After the $3 \% \mathrm{NaOH}$ pretreatment at $60{ }^{\circ} \mathrm{C}$, the $\mathrm{CrI}$ increased to

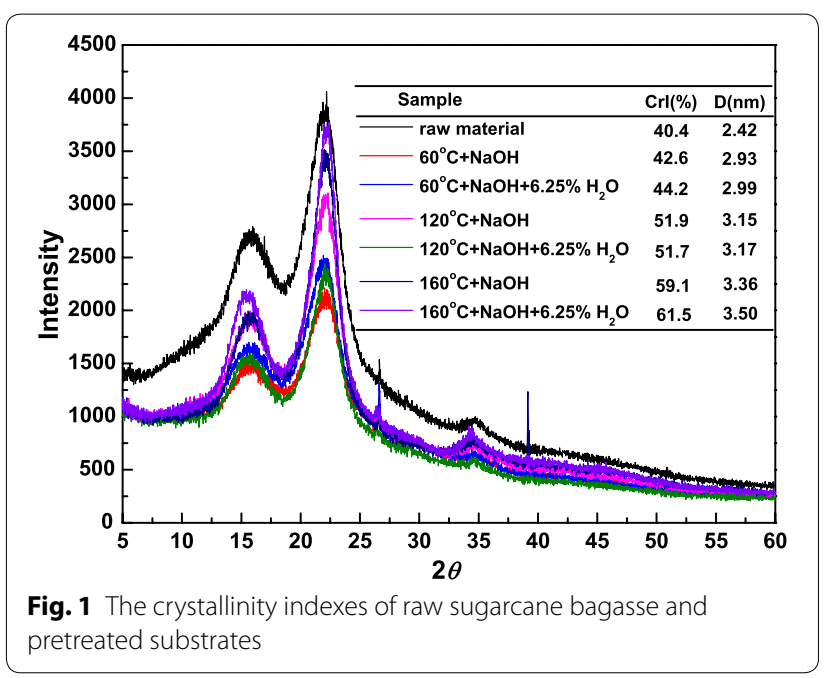

42.6\%. This phenomenon was due to the dissolution/degradation of amorphous hemicellulose and lignin, leading to the increased content of cellulose in pretreated substrates, as confirmed in Table 1 [20]. For $\mathrm{NaOH}$ pretreatment, as the temperature increased from 120 to $160{ }^{\circ} \mathrm{C}$, the $\mathrm{CrI}$ increased gradually from 51.9 to $59.1 \%$. However, no distinct change in cellulose content was observed. This could be ascribed that more amorphous cellulose were removed at higher pretreatment temperature, and the intensity of crystalline peaks at $15.5^{\circ}$ and $22.0^{\circ}$, corresponding to the crystalline cellulose, increased gradually with the elevation of pretreatment temperature. For AHP pretreatment at $60{ }^{\circ} \mathrm{C}$, the $\mathrm{CrI}$ increased to $44.2 \%$, which was a little higher than that with only $\mathrm{NaOH}$, attributing to the larger removal of xylan, AIL, and amorphous cellulose. As the pretreatment temperature was increased from 120 to $160^{\circ} \mathrm{C}$, the $\mathrm{CrI}$ increased from 51.7 to $61.5 \%$, attributing to the enhancement of cellulose content and the removal of amorphous cellulose. Due to the degradation of hemicellulose, lignin, and amorphous cellulose, the intact structure composed of three main constitutes was ruptured, providing more cellulose fibers for the 
accessibility of enzyme, and enhancing the enzymatic digestibility [21].

In addition, the average cellulose crystallite size (D) was determined according to the Scherrer equation. As shown in Fig. 1, the average size of untreated material was $2.42 \mathrm{~nm}(002)$. After the $\mathrm{NaOH}$ pretreatment at $60{ }^{\circ} \mathrm{C}$, its average size reached $2.93 \mathrm{~nm}$, which was larger than that of native material. As the pretreatment temperature was raised from 120 to $160^{\circ} \mathrm{C}$, the average size went on increasing gradually to $3.36 \mathrm{~nm}$. This result was not agreed with that the crystalline size became smaller after pretreatment due to the disruption of cellulose crystallinity $[22,23]$. Hence, it was presumed that the crystalline cellulose might be reformed or recrystallized after $\mathrm{NaOH}$ pretreatment, leading to the increment of average size of cellulose crystallite [24, 25]. For AHP pretreatment, as the pretreatment temperature was elevated, the average size presented the same tendency with $\mathrm{NaOH}$-pretreated substrates, increased gradually from 2.99 to $3.50 \mathrm{~nm}$.

To investigate the changes of morphological structure after pretreatment, SEM images of untreated and pretreated substrates were observed and presented in Additional file 1: Figure S1. The raw sugarcane bagasse showed an intact and smooth surface with well-ordered fiber bundles, which was not easy for the accessibility of enzyme to cellulose. After $\mathrm{NaOH}$ pretreatment or AHP pretreatment at $60{ }^{\circ} \mathrm{C}$, the fibers became rough, loose, and disrupt with cracks, pores, and debris on the surface [7]. These changes could be ascribed to the degradation of hemicellulose/lignin due to the fibers swelling, linkages disruption between lignin and hemicellulose, as well as the radical reaction of $\mathrm{OH}$ and lignin $[18,26]$. As pretreatment temperature raised from 60 to $160{ }^{\circ} \mathrm{C}$, most of the fibers were disconnected and well-separated with more obvious pores and fragments appeared on the surface of substrates, which could reduce the structure barrier and provide more surface for the accessibility of cellulase, and improve the subsequent enzymatic saccharification [23].

FT-IR spectroscopy (Additional file 1: Figure S2) was used to analysis the structural and chemical changes of sugarcane bagasse after pretreatment. The prominent peaks at $1740 \mathrm{~cm}^{-1}$ attributed to the vibrations of acetyl/ carbonyl groups in hemicellulose or carboxylic groups in lignin. It became weaken after $\mathrm{NaOH}$ or AHP pretreatment, and almost disappeared after pretreated at $160{ }^{\circ} \mathrm{C}$, suggesting that the carboxylic and ester bonds in hemicellulose and lignin were ruptured $[7,27]$. The signals of the aromatic lignin ring at $1510 \mathrm{~cm}^{-1}$ and $1604 \mathrm{~cm}^{-1}$ became intensive after pretreatment. This result suggested that the hemicellulose degradation was faster than delignification during $\mathrm{NaOH}$ or AHP pretreatment, which did not decrease the lignin content in pretreated substrates. The peak at $898 \mathrm{~cm}^{-1}$ attributed to the $\beta$-glycosidic linkages in cellulose, became intensive after pretreatment, which was in agreement with the increment of glucan after pretreatment, as confirmed in Table 1 [28]. Taken together, the FT-IR analysis was in accordance with the chemical analysis data, retained the major cellulose in pretreated substrates by selective breaking functional groups and chemical bonds, and presented an enhanced exposure of cellulose for enzyme accessibility because of the degradation of hemicellulose and lignin [7].

As is known, the thermal properties of lignocellulosic biomass associated with the chemical constitute and their structural characteristics [29]. TG and DTG analyses of untreated and pretreated substrates were detected and illustrated in Fig. 2. As shown, the original weight loss between 5.5 and $7.2 \%$ below $120{ }^{\circ} \mathrm{C}$ was corresponded to the evaporation of moisture. All samples adequately degraded between 200 and $400{ }^{\circ} \mathrm{C}$, including hemicellulose decomposition $\left(180-320{ }^{\circ} \mathrm{C}\right)$, cellulose decomposition $\left(320-400{ }^{\circ} \mathrm{C}\right)$, and lignin decomposition $\left(>360^{\circ} \mathrm{C}\right)[7]$. It was noteworthy that pretreated

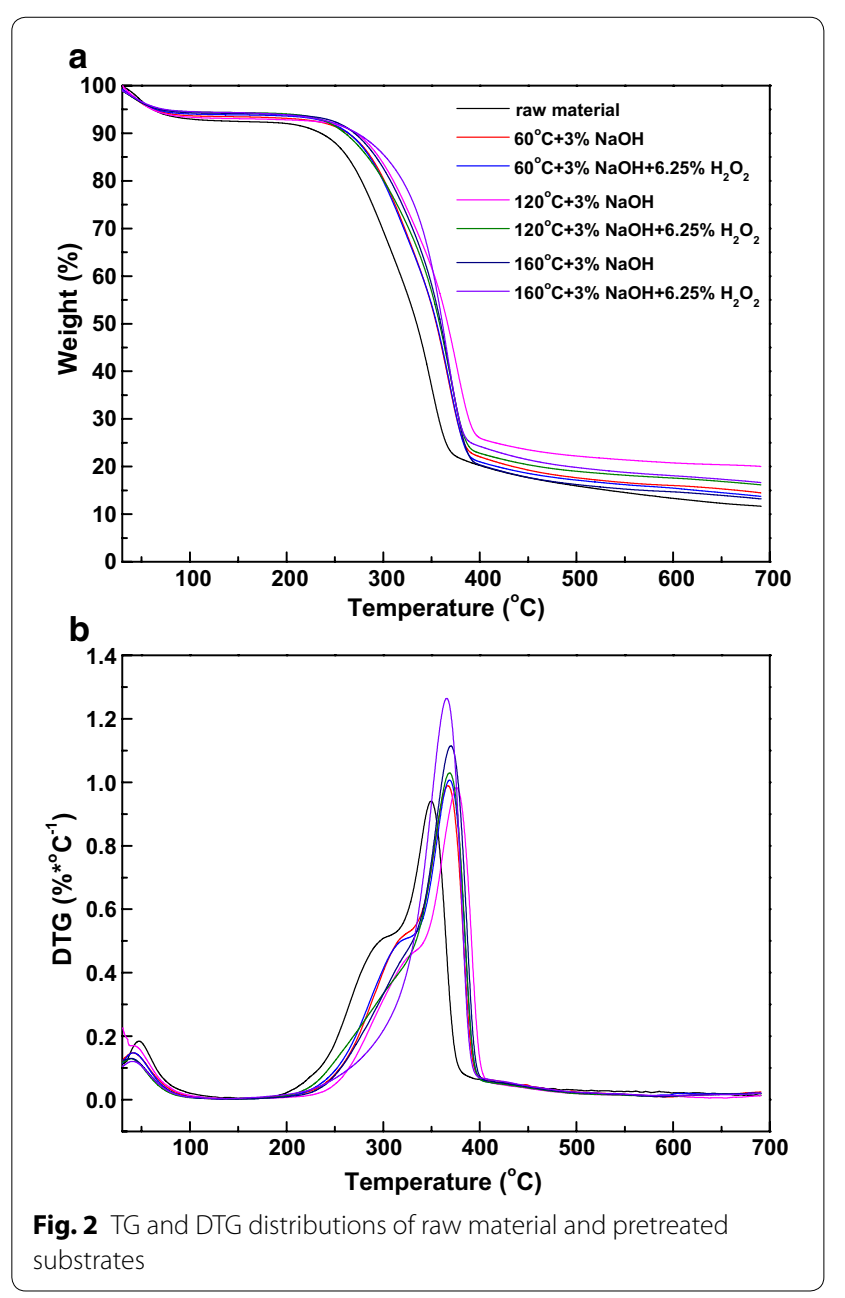


substrates presented more weight loss than the native material, which was in line with the chemical constitutes shown in Table 1 that pretreated samples contained more cellulose and lignin but less hemicellulose compared with untreated material.

For native material, two main weight loss peaks could be observed during DTG analysis. The first one was at $302{ }^{\circ} \mathrm{C}$ with DTG of $0.51 \% \mathrm{C}^{-1}$, ascribing to hemicellulose degradation. The second one occurred at $350{ }^{\circ} \mathrm{C}$ with DTG of $0.95 \% \mathrm{C}^{-1}$ due to the decomposition of cellulose/lignin, indicating that the decomposition of cellulose/lignin were more refractory than that of hemicellulose [30]. After $\mathrm{NaOH}$ or AHP pretreatment at $60^{\circ} \mathrm{C}$ or $120{ }^{\circ} \mathrm{C}$, the DTG presented similar curves (two main weight loss peaks) with raw material. However, as the pretreatment temperature increased from 60 to $120{ }^{\circ} \mathrm{C}$, the first peak became diminished gradually because of the removal of hemicellulose. This phenomenon indicated that $\mathrm{NaOH} / \mathrm{AHP}$ pretreatment modified the biomass compositions, leading to the appearance of specific properties revealed by the DTG curves. However, when the pretreatment temperature was elevated to $160{ }^{\circ} \mathrm{C}$, there was only one main weight loss peak on DTG curves, which was consistent with the degradation of cellulose/ lignin. The maximum temperatures of weight loss peaks for the $\mathrm{NaOH}$ - and AHP-pretreated substrates at 60 , 120 , and $160{ }^{\circ} \mathrm{C}$ were $367,369,376,369,370$, and $366^{\circ} \mathrm{C}$, respectively, which were all higher than that of raw material $\left(350^{\circ} \mathrm{C}\right)$. This phenomenon could be concluded that the degradation of partial hemicellulose and lignin during $\mathrm{NaOH}$ or AHP pretreatment increased the proportion of crystalline cellulose, as shown in Fig. 1. Cellulose crystals are thermally stable due to its rich hydrogen bonds, strong cellulose chains, and high polymerization degree, which contributed to the higher decomposition temperature and thermal stability of pretreated samples [7]. Furthermore, the residual lignin in pretreated substrates might also increase the decomposition temperature.

\section{Effect of pretreatment conditions on enzymatic saccharification}

Based on the above investigation, it is revealed that the crystallinity, average size, surface area, redistribution of components contents in sugarcane bagasse were greatly modified by the $\mathrm{NaOH}$ and AHP pretreatment. Hence, to explore the influence of structural and compositional changes on enzymatic saccharification, the glucose yields of pretreated substrates as a function of incubation time were investigated and presented in Fig. 3. For native material, the glucose yield went up gradually to $22.4 \%$ after $72 \mathrm{~h}$ [13]. After pretreatment, all samples performed higher glucose yield than the native material. However, when the pretreatment temperature was
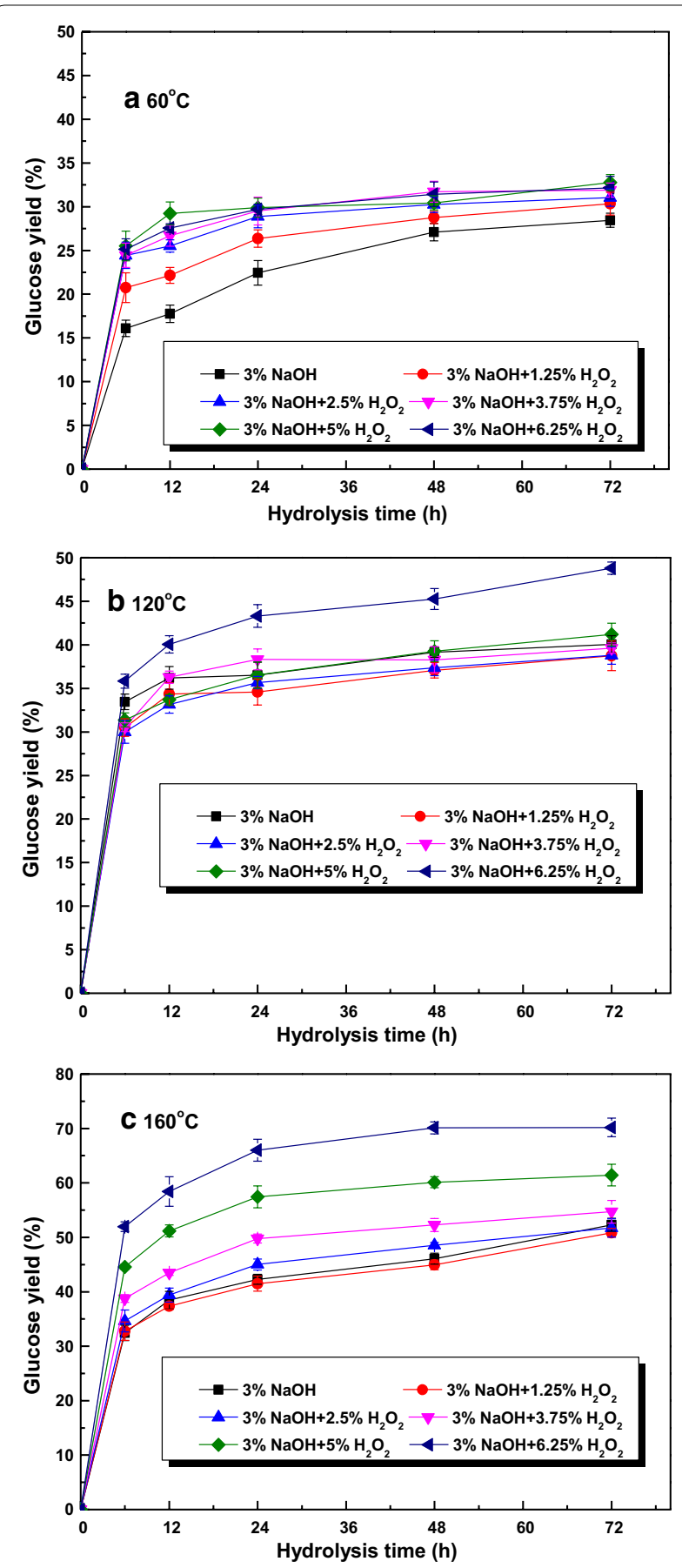

Fig. 3 Glucose yield after $\mathrm{NaOH}$ and AHP pretreatment under different temperatures

$60{ }^{\circ} \mathrm{C}$, only a marginal improvement in glucose yield could be observed no matter for $\mathrm{NaOH}$ or AHP-pretreated substrates. Increasing the $\mathrm{H}_{2} \mathrm{O}_{2}$ loading during AHP pretreatment did not lead to great enhancement in enzymatic hydrolysis. This phenomenon was ascribed to the slight degradation of xylan and lignin, which did 
not cause extensive breakdown of the intact structure of native material [18]. When the pretreatment temperature was risen to $120^{\circ} \mathrm{C}$, the $\mathrm{NaOH}$-pretreated solid yielded glucose yield about $40 \%$ of after $72 \mathrm{~h}$. When AHP pretreatment were conducted with $1.25-3.75 \% \mathrm{H}_{2} \mathrm{O}_{2}$, the glucose yields were a little lower than that obtained from $\mathrm{NaOH}$ substrate [10]. As the $\mathrm{H}_{2} \mathrm{O}_{2}$ loading increased to $6.25 \%$, the glucose yield increased gradually to $48.8 \%$, attributing to the degradation of hemicellulose (48.7\%) and AIL (26\%) over pretreatment process, which provided more cellulose for the accessibility of enzyme and was in consistent with the previous literatures $[18,26]$. When pretreatment temperature of $160{ }^{\circ} \mathrm{C}$ was implemented, $52.3 \%$ of glucose could be yielded after $72 \mathrm{~h}$ for $\mathrm{NaOH}$-pretreated substrate. For AHP pretreatment, the glucose yield showed an increased tendency with the increment of $\mathrm{H}_{2} \mathrm{O}_{2}$ dosage, and reached the highest yield of $70.2 \%$ with $6.25 \% \mathrm{H}_{2} \mathrm{O}_{2}$, representing $80.7 \%$ of glucose in pretreated substrate. This enhancement was due to the potential effect of AHP pretreatment on delignification (38.9\%) and hemicellulose removal (84.7\%) without significant cellulose degradation $(<13 \%)$, which damaged the intact structure, increased porosity and surface area, made it easy for the accessibility of cellulase [31-33].

According to the results in Fig. 3, enzymatic saccharification of pretreated substrate was accelerated greatly because of the degradation of hemicellulose and lignin, leading to the increment of porosity of biomass, providing more cellulose for the accessibility of cellulase, reducing the nonspecific bonding to enzyme, thus enhancing the enzymatic digestibility. To determine that the removal of hemicellulose/lignin were positively related to the enhancement of enzymatic saccharification, the glucose yields were plotted against the removal of xylan/ AIL, and the results were depicted in Fig. 4. When there was no lignin and hemicellulose removal, that is to say, native material was regarded as substrate for enzymatic saccharification, only $22.4 \%$ of glucose could be obtained. A clear relationship was consistently observed between the removal of xylan/AIL and glucose yield. When the removal of xylan/AIL were increased from 25.5 to $84.7 \%$ and 11.9 to $38.9 \%$, respectively, the glucose yields linearly and positively increased from 28.4 to $70.2 \%$ with $r^{2}$ of 0.7494 and 0.8186 , respectively. Similar phenomenon was observed for the $\mathrm{H}_{2} \mathrm{O}_{2}-\mathrm{Na}_{2} \mathrm{CO}_{3}$ pretreatment of corn stover [34].

\section{The enhanced production of glucose with Tween 80}

In order to go on improving the enzymatic efficiency, several subsequent experiments with Tween 80 (150 mg/g substrate) were conducted, and the results were illustrated in Fig. 5. The glucose yields of all samples were enhanced greatly with Tween 80 . For substrates

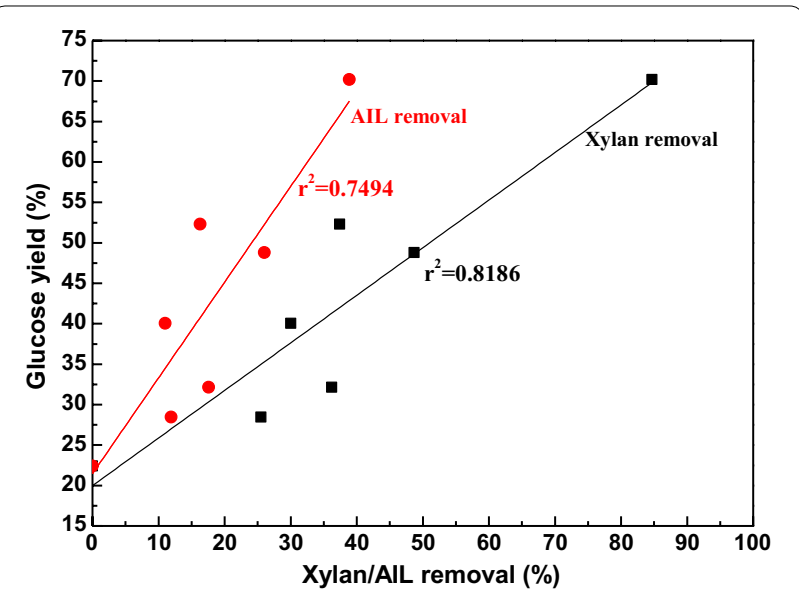

Fig. 4 Correlation between glucose yield and xylan/AlL removal

pretreated with $\mathrm{NaOH}$ or AHP at $60^{\circ} \mathrm{C}$, the control glucose yields after $6 \mathrm{~h}$ without additive were $16.1 \%$ and $25.1 \%$, respectively. With the addition of Tween 80 , the glucose yields increased to $22.0 \%$ and $32.8 \%$ with the increased yields of $36.6 \%$ and $30.7 \%$, respectively. This enhancement could be concluded that the addition of Tween 80 reduced the cellulase adsorption on lignin by hydrophobic interactions, increased desorption of cellulase in the substrate fibers, provided more cellulase for enzymatic saccharification, resulting in the improvement of enzymatic efficiency [33, 35, 36]. After hydrolysis for $72 \mathrm{~h}$, the glucose yields with Tween 80 increased gradually to $30.8 \%$ and $39.7 \%$, respectively, which were higher than that without Tween 80 (28.4\% and 32.2\%) [37]. However, the increased yields did not increase, but reduced to $8.4 \%$ and $23.5 \%$, respectively. This phenomenon could be interpreted in two ways. First, there was not enough cellulase provided for cellulose hydrolysis because of the non-desorption of it from enzymatic substrate [21]. Second, substrates became more recalcitrant. The residual cellulose was enriched in crystalline portions encapsulated by lignin and hemicellulose, the mild pretreatment conditions were not enough for the dissolution of it, which impeded the enzymatic efficiency [13,33].

When the pretreatment temperature was increased to $120{ }^{\circ} \mathrm{C}$, for $\mathrm{NaOH}$-pretreated solid, the glucose yields increased gradually with extended time. However, the increased yields with Tween 80 presented the contrary tendency with other substrates, increased gradually from 10.6 to $16.8 \%$ over time from $6 \mathrm{~h}$ to $72 \mathrm{~h}$. When AHPpretreated substrate was conducted, the glucose yields with Tween 80 increased gradually to $50.9 \%$ after $72 \mathrm{~h}$, and the increased yields decreased from $12.1 \%(6 \mathrm{~h})$ to $4.4 \%(72 \mathrm{~h})$, which presented the same tendency with that pretreated at $60{ }^{\circ} \mathrm{C}$ using AHP pretreatment. For 

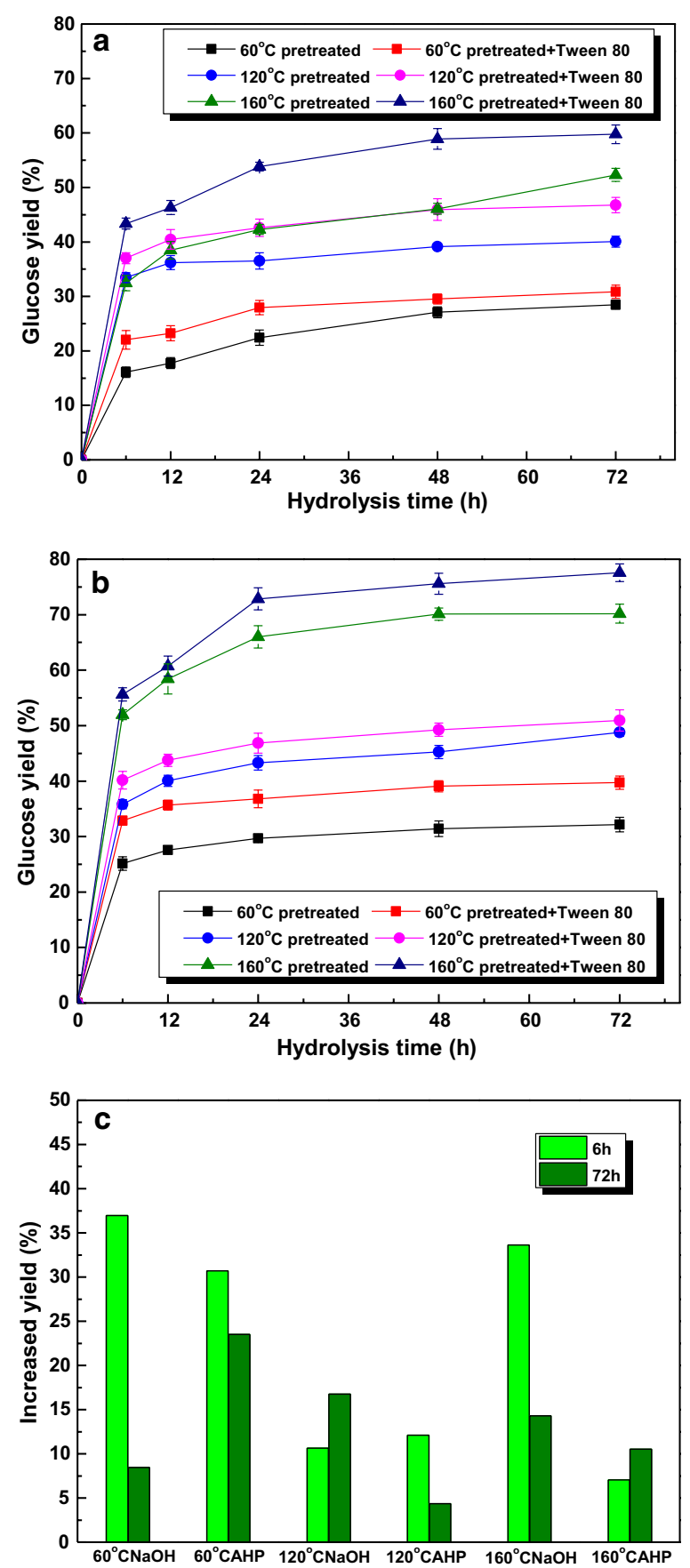

Fig. 5 Glucose yields and increased yields obtained from different pretreated substrates with the addition of Tween 80 (a $\mathrm{NaOH}$-pretreated substrates, $\mathbf{b} \mathrm{NaOH}+6.25 \% \mathrm{H}_{2} \mathrm{O}_{2}$ pretreated substrates, c increased yields with Tween 80 )

substrate pretreated at $160{ }^{\circ} \mathrm{C}$ with $\mathrm{NaOH}$, with the addition Tween 80, the glucose yields after $72 \mathrm{~h}$ increased from 52.3 to $59.8 \%$. And the increased yields decreased greatly from $33.6 \%$ to $14.3 \%$ as the hydrolysis time was prolonged from $6 \mathrm{~h}$ to $72 \mathrm{~h}$. A possible reason for this decrease is that the available glucose in pretreated substrate which can be released by enzymatic hydrolysis became less with extended time. When $160^{\circ} \mathrm{C}$ AHP-pretreated substrate was used for enzymatic hydrolysis, the glucose yield with Tween 80 after $72 \mathrm{~h}$ increased from 70.2 to $77.6 \%$, the highest glucose yield represented $89.1 \%$ of glucose in pretreated substrate. However, as the hydrolysis time was stretched, the increased yields of glucose did not decrease, but increased from 7.0 to $10.5 \%$.

Pretreatment was the essential step for the bioconversion of lignocellulosic biomass to bioethanol and biochemicals. The results in this study suggested that $3 \%$ $\mathrm{NaOH}$ and $6.25 \% \mathrm{H}_{2} \mathrm{O}_{2}$ pretreatment provided a promising technology to achieve high glucose yield with addition of Tween 80 from sugarcane bagasse. This proposed pretreatment not only generated high glucose yield, but also reduced the cost of the bio-refinery process due to the lower loading of chemicals and gradual conditions.

\section{Methods \\ Materials}

Sugarcane bagasse was collected from Shaoguan, China. They were ground using a mill to obtain the powders with diameter below $1 \mathrm{~mm}$. The chemical analysis of native sugarcane bagasse was detected based on the protocol NREL/TP-510-42618 proposed by the NREL [38]. It contained $41.2 \%$ cellulose, $22.8 \%$ hemicellulose [including $20.2 \%$ xylan, $1.8 \%$ arabinan, $0.8 \%$ galactan), $25.2 \%$ lignin (containing $22.0 \%$ acid insoluble lignin (AIL), 3.2\% acid soluble lignin (ASL)], and 3.6\% ash.

\section{Pretreatment and enzymatic hydrolysis}

The operating conditions of AHP pretreatment were as follows: $3 \mathrm{wt} \% \mathrm{NaOH}$ and 1.25-6.25 wt $\% \mathrm{H}_{2} \mathrm{O}_{2}$ (both based on dry sugarcane bagasse), temperature $60-160{ }^{\circ} \mathrm{C}$, time 1-4 h, and solid/liquid ratio of 1:10. Meanwhile, the pretreatment with only $\mathrm{NaOH}(3 \mathrm{wt} \%)$ under different temperatures were also carried out. The mild pretreatment conditions of $60^{\circ} \mathrm{C}$ for $4 \mathrm{~h}$ were employed in a shaker. However, the higher pretreatment reactions at $120{ }^{\circ} \mathrm{C}$ for $2 \mathrm{~h}$ or $160{ }^{\circ} \mathrm{C}$ for $1 \mathrm{~h}$ were tested in a $1 \mathrm{~L}$ Parr reactor. After the reaction was completed, iced water was used to stop the reaction immediately. Then, the solids were separated by filtration and washed thoroughly with de-ionized water, and stored in refrigerator for further use.

The enzymatic saccharification experiments were performed at $2 \%(\mathrm{w} / \mathrm{v})$ solid loading in $50 \mathrm{mM}$ sodium acetate buffer ( $\mathrm{pH} 4.8)$ in a $250 \mathrm{~mL}$ Erlenmeyer flask. Cellic CTec2, with a cellulytic activity of $90 \mathrm{FPU} / \mathrm{mL}$, was added at loading of $20 \mathrm{FPU} / \mathrm{g}$ dry substrate. Then, the mixtures were incubated in a shaker at $50{ }^{\circ} \mathrm{C}$ and $150 \mathrm{rpm}$ [13]. After enzymatic saccharification for $6,12,24,48$, and 
$72 \mathrm{~h}$, a small amount of liquor was taken out from the hybrid and centrifuged at 10,000 rpm for several minutes to quantify the sugars. To determine the enhancement of additive on enzymatic saccharification, $150 \mathrm{mg}$ Tween 80 was acceded to the hybrid based on per $g$ dry substrate. For the complete interaction between Tween 80 and substrate, they should be incubated with hybrid for $30 \mathrm{~min}$ before the addition of cellulase.

\section{Analytical methods}

The chemical compositions of untreated and pretreated solids, and sugars obtained from enzymatic saccharification were determined by HPLC (Shimadzu, Japan) equipped with a of SUGAR SH1011 column and a refractive index detector at $50{ }^{\circ} \mathrm{C}$ with $1.0 \mathrm{~mL} / \mathrm{min}$ of $5 \mathrm{mM}$ $\mathrm{H}_{2} \mathrm{SO}_{4}$ as eluates [39]. The glucose yield obtained from enzymatic hydrolysis and the increased yields of glucose with Tween 80 were determined based on the following equations:
80 played remarkable performances in promoting the glucose yield during enzymatic hydrolysis by stabilizing and protecting the enzyme activity. The highest glucose yield of $77.6 \%$ was obtained after pretreatment at $160{ }^{\circ} \mathrm{C}$ for $60 \mathrm{~min}$ with $6.25 \% \mathrm{H}_{2} \mathrm{O}_{2}$ and the addition of Tween 80 , representing $89.1 \%$ of glucose in pretreated substrate.

\section{Additional file}

Additional file 1: Figure S1. SEM images of raw material and pretreated substrates at $\times 2000$ magnification. Figure S2. FTIR spectra of untreated and pretreated samples with different pretreatment conditions.

\section{Authors' contributions}

$\mathrm{HZ}$ carried out all the experiments and drafted the manuscript. SH and JZ performed the characterization of biomass samples. WW and JX helped to revise the manuscript. All authors read and approved the final manuscript.

$$
\begin{aligned}
& \text { Glucose yield }(\%)=\frac{\text { Glucose produced in enzymatic hydrolysis }}{\text { Glucan amount in raw material } * 1.11} \times 100 \% \\
& \text { Increased yield }(\%)=\frac{\text { Glucose yield with surfactant }- \text { glucose yield without surfactant }}{\text { Glucose yield without surfactant }} \times 100 \% .
\end{aligned}
$$

\section{Characterization of untreated and pretreated solids}

Cellulose crystallinity and the average crystallite size (D) of untreated and pretreated sugarcane bagasse were detected by an X-ray diffractometer (D8-ADVANCE, Bruker, Germany) using $\mathrm{Cu}$ radiation $(k=0.1541 \mathrm{~nm})$. The scattering angles $(2 \theta)$ ranged from $5^{\circ}$ to $60^{\circ}$. The CrI and crystallite size (D) were calculated based on Segal method and Scherrer equation, respectively [13, 32, 40]. SEM was used to measure the morphological changes of substrates (FEI Verios 460, USA). The FT-IR spectroscopy was evaluated by a Tensor 27 FT-IR spectrometer (Bruker, Germany) in the range of resolution between 4000 and $400 \mathrm{~cm}^{-1}$. The thermogravimetric and differential thermogravimetric (TG/DTG) analysis was conducted with an analyzer TG-Q500 (TA instruments, USA) under $\mathrm{N}_{2}$ atmosphere.

\section{Conclusions}

AHP pretreatment of sugarcane bagasse under different temperatures was applied to enhance enzymatic saccharification. It was demonstrated that there was a positive correlation between $\mathrm{H}_{2} \mathrm{O}_{2}$ loading and glucose yield, ascribing to the widespread degradation of hemicellulose and lignin, which disrupted the matrix structure and provided more cellulose for the accessibility of cellulase. Moreover, the addition of Tween

\section{Author details}

${ }^{1}$ College of Forestry and Landscape Architecture, Key Laboratory of Energy Plants Resource and Utilization, Ministry of Agriculture, South China Agricultural University, Guangzhou 510642, People's Republic of China. ${ }^{2}$ CAS Key Laboratory of Renewable Energy, Guangzhou Institute of Energy Conversion, Guangzhou 510640, People's Republic of China. ${ }^{3}$ College of Light Industry and Food Engineering, Nanjing Forestry University, Nanjing 210037, People's Republic of China.

\section{Acknowledgements}

This work was supported by the National Natural Science Foundation of China (21606091), CAS Key Laboratory of Renewable Energy, Guangzhou Institute of Energy Conversion (Y807k51001).

\section{Competing interests}

The authors declare that they have no competing interests.

Availability of supporting data

All data generated or analyzed during this study are included in this published article.

Consent for publication

All authors have approved the manuscript to be published.

Ethics approval and consent to participate

Not applicable.

Funding

Funding sources have been addressed in the Acknowledgements.

\section{Publisher's Note}

Springer Nature remains neutral with regard to jurisdictional claims in published maps and institutional affiliations. 
Received: 18 February 2019 Accepted: 25 April 2019

Published online: 03 May 2019

\section{References}

1. Mokomele T, da Sousa Costa L, Balan V, van Rensburg E, Dale BE, Görgens JF. Ethanol production potential from AFEX ${ }^{\mathrm{TM}}$ and steam-exploded sugarcane residues for sugarcane biorefineries. Biotechnol Biofuels. 2018;11:1-21.

2. Batalha LAR, Han Q, Jameel H, Chang HM, Colodette JL, Gomes FJB. Production of fermentable sugars from sugarcane bagasse by enzymatic hydrolysis after autohydrolysis and mechanical refining. Bioresour Technol. 2015;180:97-105

3. Ji Z, Zhang X, Ling Z, Zhou X, Ramaswamy S, Xu F. Visualization of Miscanthus $x$ giganteus cell wall deconstruction subjected to dilute acid pretreatment for enhanced enzymatic digestibility. Biotechnol Biofuels. 2015:8:103.

4. Auxenfans T, Cronier D, Chabbert B, Paes G. Understanding the structural and chemical changes of plant biomass following steam explosion pretreatment. Biotechnol Biofuels. 2017;10:36.

5. Alvira P, Tomas-Pejo E, Ballesteros M, Negro MJ. Pretreatment technologies for an efficient bioethanol production process based on enzymatic hydrolysis: a review. Bioresour Technol. 2010;101:4851-61.

6. Li M, Pattathil S, Hahncde MG, Hodge DB. Identification of features associated with plant cell wall recalcitrance to pretreatment by alkaline hydrogen peroxide in diverse bioenergy feedstocks using glycome profiling. RSC Adv. 2014:4:17282-92.

7. Phitsuwan P, Sakka K, Ratanakhanokchai K. Structural changes and enzymatic response of Napier grass (Pennisetum purpureum) stem induced by alkaline pretreatment. Bioresour Technol. 2016;218:247-56.

8. Bansal N, Bhalla A, Pattathil S, Adelman SL, Hahn MG, Hodge DB, Hegg EL. Cell wall-associated transition metals improve alkaline-oxidative pretreatment in diverse hardwoods. Green Chem. 2016;18:1405-15.

9. Li M, Wang J, Yang Y, Xie G. Alkali-based pretreatments distinctively extract lignin and pectin for enhancing biomass saccharification by altering cellulose features in sugar-rich Jerusalem artichoke stem. Bioresour Technol. 2016;208:31-41.

10. Alvarez-Vasco C, Zhang X. Alkaline hydrogen peroxide (AHP) pretreatment of softwood: enhanced enzymatic hydrolysability at low peroxide loadings. Biomass Bioenergy. 2017;96:96-102.

11. Mittal A, Katahira R, Donohoe BS, Black BA, Pattathil S, Stringer JM, Beckham GT. Alkaline peroxide delignification of corn stover. ACS Sustain Chem Eng. 2017;5(7):6310-21.

12. Yuan ZY, Wen YB, Kapu NS. Ethanol production from bamboo using mild alkaline pre-extraction followed by alkaline hydrogen peroxide pretreatment. Bioresour Technol. 2018;247:242-9.

13. Zhang H, Fan M, Li X, Zhang A, Xie J. Enhancing enzymatic hydrolysis of sugarcane bagasse by ferric chloride catalyzed organosolv pretreatment and Tween 80. Bioresour Technol. 2018;258:295-301.

14. Yan $L$, Zhang L, Yang B. Enhancement of total sugar and lignin yields through dissolution of poplar wood by hot water and dilute acid flow through pretreatment. Biotechnol Biofuels. 2014;7:1-15.

15. Kim W, Gamo Y, Sani YM, Wusiman Y, Ogawa S, Karita S, Goto M. Effect of Tween 80 on hydrolytic activity and substrate accessibility of carbohydrolase I (CBH I) from Trichoderma viride. Asian Australas J Anim. 2006;19:684-9.

16. Rabetafika HN, Bchir B, Blecker C, Paquot M, Wathelet B. Comparative study of alkaline extraction process of hemicelluloses from pear pomace. Biomass Bioenergy. 2014;61:254-64.

17. Song $X$, Jiang $Y$, Rong $X$, Wei W, Wang $S$, Nie S. Surface characterization and chemical analysis of bamboo substrates pretreated by alkali hydrogen peroxide. Bioresour Technol. 2016;216:1098-101.

18. Cabrera E, Munoz MJ, Martin R, Caro I, Curbelo C, Diaz AB. Alkaline and alkaline peroxide pretreatments at mild temperature to enhance enzymatic hydrolysis of rice hulls and straw. Bioresour Technol. 2014;167:1-7.

19. Alvarez-Vasco C, Zhang X. Alkaline hydrogen peroxide pretreatment of softwood: hemicellulose degradation pathways. Bioresour Technol. 2013;150:321-7.
20. Liu H, Pang B, Zhao YD, Lu J, Han Y, Wang HS. Comparative study of two different alkali-mechanical pretreatments of corn stover for bioethanol production. Fuel. 2018;221:21-7.

21. Kumar R, Wyman CE. Cellulase adsorption and relationship to features for corn stover solids produced by leading pretreatments. Biotechnol Bioeng. 2009;103:252-67.

22. Zhang JZ, Ma XX, Yu JL, Zhang X, Tan TW. The effects of four different pretreatments on enzymatic hydrolysis of sweet sorghum bagasse. Bioresour Technol. 2011;102:4585-9.

23. Sun FB, Wang L, Hong JP, Ren JL, Du FG, Hu JG, Zhang ZY, Zhou BW. The impact of glycerol organosolv pretreatment on the chemistry and enzymatic hydrolyzability of wheat straw. Bioresour Technol. 2015;187:354-61.

24. Tang S, Liu R, Sun FF, Dong C, Wang R, Gao Z, Zhang Z, Xiao Z, Li C, $\mathrm{Li} \mathrm{H}$. Bioprocessing of tea oil fruit hull with acetic acid organosolv pretreatment in combination with alkaline $\mathrm{H}_{2} \mathrm{O}_{2}$. Biotechnol Biofuels. 2017;10:1-12.

25. Gurgel LVA, Marabezi K, Ramos LA, Curvelo AADS. Characterization of depolymerized residues from extremely low acid hydrolysis (ELA) of sugarcane bagasse cellulose: effects of degree of polymerization, crystallinity and crystallite size on thermal decomposition. Ind Crop Prod. 2012;36:560-71.

26. Correia JAD, Marques JE, Goncalves LRB, Rocha MVP. Alkaline hydrogen peroxide pretreatment of cashew apple bagasse for ethanol production: study of parameters. Bioresour Technol. 2013;139:249-56.

27. Flauzino Neto WP, Silverio HA, Dantas NO, Pasquini D. Extraction and characterization of cellulose nanocrystals from agro-industrial residue-soy hulls. Ind Crop Prod. 2013:42:480-8.

28. Ravindran R, Sarangapani C, Jaiswal S, Cullen PJ, Jaiswal AK. Ferric chloride assisted plasma pretreatment of lignocellulose. Bioresour Technol. 2017;243:327-34

29. Grimaldi MP, Marques MP, Laluce C, Cilli EM, Sponchiado SRP. Evaluation of lime and hydrothermal pretreatments for efficient enzymatic hydrolysis of raw sugarcane bagasse. Biotechnol Biofuels. 2015:8:1-14.

30. Yu J, Paterson N, Blamey J, Millan M. Cellulose, xylan and lignin interactions during pyrolysis of lignocellulosic biomass. Fuel. 2017;191:140-9.

31. Yuan TQ, Wang W, Zhang LM, Sun RC. Reconstitution of cellulose and lignin after [C2mim] [OAc] pretreatment and its relation to enzymatic hydrolysis. Biotechnol Bioeng. 2013;110:729-36.

32. Zhang H, Wu S. Generation of lignin and enzymatically digestible cellulose from ethanol-based organosolv pretreatment of sugarcane bagasse. Cellulose. 2015;22:2409-18.

33. Mesquita JF, Ferraz A, Aguiar A. Alkaline-sulfite pretreatment and use of surfactants during enzymatic hydrolysis to enhance ethanol production from sugarcane bagasse. Bioprocess Biosyst Eng. 2016;39:441-8.

34. Gong W, Liu C, Mu X, Du H, Lv D, Li B, Han S. Hydrogen peroxide-assisted sodium carbonate pretreatment for the enhancement of enzymatic saccharification of corn stover. ACS Sustain Chem Eng. 2015;3:3477-85.

35. Zhao X, Zhang L, Liu D. Biomass recalcitrance Part I: the chemical compositions and physical structures affecting the enzymatic hydrolysis of lignocellulose. Biofuels Bioprod Biorefin. 2012;6:465-82.

36. Li Y, Sun Z, Ge X, Zhang J. Effects of lignin and surfactant on adsorption and hydrolysis of cellulases on cellulose. Biotechnol Biofuels. 2016;9:1-9.

37. Jin W, Chen L, Hu M, Sun D, Li A, Li Y, Hu Z, Zhou S, Tu Y, Xia T, Wang Y, Xie G, Li Y, Bai B, Peng L. Tween-80 is effective for enhancing steamexploded biomass enzymatic saccharification and ethanol production by specifically lessening cellulase absorption with lignin in common reed. Appl Energy. 2016;175:82-90.

38. Sluiter A, Hames B, Ruiz R, Scarlata C, Sluiter J, Templeton D, Crocker D. Determination of structural carbohydrates and lignin in biomass. National Renewable Energy Laboratory; 2008.

39. Yu Q, Tan X, Zhuang X, Wang Q, Wang W, Qi W, Zhou G, Luo Y, Yuan Z. Co-extraction of soluble and insoluble sugars from energy sorghum based on a hydrothermal hydrolysis process. Bioresour Technol. 2016:221:111-20.

40. Segal L, Creely L, Martin AE. An empirical method for estimating the degree of crystallinity of native cellulose using X-ray diffractometer. Text Res J. 1959:29:786-94. 